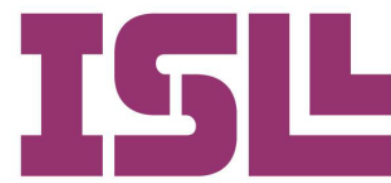

Número 4.

Julio de 2015

\section{Enseñanza de la ortografía, tratamiento didáctico y consideraciones de los docentes de Educación Primaria de la provincia de Almería}

\author{
Ana Fernández-Rufete Navarro \\ Universidad de Almería
}

Pág. 7 a la 24

\section{Keywords}

spelling, teaching, learning, education, research

\begin{abstract}
:
Through collating of the views of primary school teachers who teach the area of Spanish language and literature, this research seeks to deal with the opinions of teachers andmethodological approaches used in the teaching of writing. We establish a high concern to makespelling a priority and recognise a widespread failure in the results obtained by the students; the willingness of teachers to implement new educational proposals for

The teaching of spelling through activities involving written composition appears to be critical for teachers who claim agreed alternatives should be included in the planning in all knowledges of primary. In turn, there is the necessity of the schools are on the same page and agree lesson plans which are going to make consubstantial and hard-wearing changes on approaches and methods to be applied in the teaching of spelling and including all areas of knowledge.
\end{abstract} teaching of writing and calls for a reflection on didactic approaches is clear.

In this descriptive investigation, the questionnaire is the instrument used to collect data from teachers. The sample is established by a total of 140 teachers from 25 schools. After collecting the data, these data were analyse to get a general view of the situation of the learning of the spelling from the point of view of primary school teachers who teach the area of Spanish language and literature in Almería and province.

Forteaching, writing is basic necessity in all knowledges of primary and it is one of the quality indicators in our educational system as a basic element for the control of the written language. 


\section{Introducción}

En la actualidad, existe un sentir común entre los docentes: el cada vez más grave problema de la ortografía y las dificultades para atajarlo. Y es que, además, es un sentir entre aprendices el menosprecio por la corrección en la escritura, quizá por influencia o imposición de los nuevos dispositivos electrónicos que requieren de la instantaneidad, de la improvisación, de la velocidad y la economía lingüística, además de otras limitaciones dentro de las aulas, desde el aumento de la ratio hasta las distintas metodologías docentes.

Es un hecho el gran número de errores ortográficos que cometen los escolares a la hora de elaborar textos, las continuas impropiedades en el uso del léxico o en las construcciones gramaticales; incorrecciones que, en unos casos, se gestan en la Educación Primaria, se acentúan a lo largo de la Educación Secundaria y se siguen apreciando de manera significativa durante la enseñanza universitaria donde se llegan a apreciar graves errores que no se han subsanado y trabajado en etapas anteriores. Echauri (2010, p.1) señala que "las faltas de ortografías son una realidad omnipresente frente a la que el profesorado se siente a menudo impotente y sin saber muy bien cómo actuar".

Es observable cómo los errores ortográficos en los escolares son frecuentes y constituyen una gran preocupación para el profesorado, que manifiesta encontrar grandes dificultades a la hora de actuar sobre el error y en otros casos, cómo abordar la enseñanza de la ortografía. No solo los niños y niñas en edad escolar tienen dificultades ortográficas sino que también estudiantes universitarios poseen problemas en el correcto uso de las normas que rigen la escritura (Matteoda, 1998; Carratalá, 2002 y Díaz, 2008). Ante esta observación, he decidido plantear este estudio, con el fin de conocer que tratamiento didáctico le aporta el profesorado a la ortografía en el área de Lengua y Literatura a la misma vez, encontrar explicaciones, opiniones, creencias, posibles soluciones que aporten luz al proceso de enseñanza-aprendizaje en general, obteniendo una visión global de cómo la trabajan en el aula de Educación Primaria.

Durante la etapa de formación, son muchas horas lectivas las que los docentes dedican a la enseñanza de la ortografía (Gabarró y Puigarnau, 2010) y, por ello, es necesario, de un lado, conocer de qué manera se trabaja con esta en el aula con la finalidad de analizar cómo se adquiere esta destreza y, de otro, barajar las posibles formas de actuar. Así que esta investigación cuantitativa pretende analizar cuáles son las estrategias y enfoques empleados por el profesorado de Almería y provincia para trabajar con la ortografía en el aula y cuáles son sus recursos ante los errores ortográficos del alumnado. Por tanto, se plantea la necesidad de descubrir si el enfoque didáctico o forma de enseñar que utiliza el profesorado es el idóneo para subsanar estos errores y de qué manera conseguirlo. Sin duda, un uso correcto de la ortografía (de la

ISL, vol. 4, 2015, págs. 7-24 ISNN: 2340-8685
Fernández-Rufete Navarro, A (2015): Enseñanza de la ortografía, tratamiento didáctico y consideraciones de los docentes de Educación Primaria de la provincia de Almería, Investigaciones Sobre Lectura, 4, 7-24. 
palabra, de la oración) constituye un elemento básico del dominio del lenguaje escrito (Zayas, 1995).

La ortografía está vigente en cualquier actividad educativa y, últimamente, está adquiriendo más relevancia la preocupación docente porque los escritos de los escolares se encuentran plagados de multitud de faltas de ortografía. Esto hace plantearnos, de un lado, en qué consiste su enseñanza; de otro, cómo se debe aplicar. Según Camps, Millán, Montserrat y Cabré (2004, pp.38-39) convendría "recordar que aprender a escribir no es aprender ortografía y que, en cambio, la ortografía es un aspecto socialmente importante de la lengua escrita”.

Otro motivo que me lleva a realizar esta investigación es que no hay ningún estudio similar en Almería y provincia; por tanto, trabajar esta temática y poder descubrir qué postura adopta el profesorado en relación con este aspecto de la enseñanza de la Lengua, que muchas veces resulta ardua. En general, existen pocos estudios que profundicen sobre el tratamiento, enfoque didáctico y evaluación que recibe la enseñanza de la ortografía en un aula de Primaria; García (2001) considera que no ha sido la ortografía un tema prioritario para los especialistas de la lengua, a pesar de la gran cantidad de carencias que hay en su aplicación didáctica y la necesidad de renovación de la misma.

\subsection{La enseñanza y aprendizaje de la ortografía: Enfoques, métodos y técnicas}

Uno de los ámbitos más importantes de la lengua es la enseñanza de la ortografía, el cual permite desarrollar habilidades intelectuales y, a través del que el alumnado desarrolla destrezas y hábitos para conformar su aparato ortográfico. Es por ello que la ortografía no solo se enseña, sino que también se aprende.

La enseñanza de la ortografía tiene que contextualizarse dentro de los aprendizajes del alumnado a través de unos métodos y unos procedimientos que el profesor, previamente, ha establecido y se encargará de poner a disposición situaciones reales de escritura que proporcionan una conexión con la escritura (Sánchez, 2009). Desde la aparición de la ortografía, como elemento de la lengua objeto de enseñanza, han sido distintos los enfoques o formas que se han ido adoptando para enseñar y trabajar con la ortografía en el aula, entre ellos: tradicional, socio-constructivista, comunicativo o funcional y por último, el PNL (Programación Neurolingüistica).

La mayoría de autores y manuales (Gómez, 2007; Bustos, 1995; Palacios, 2010 y Martínez, 2004) coinciden en un enfoque tradicional para enseñar ortografía y otros consideran que es el más empleado por el profesorado (Mesanza, 1991; Díaz, 2008 y Barberá et al., 2001). Este enfoque apuesta por la transmisión verbal de reglas, el errorcorrección-sanción, repeticiones, automatización de la escritura y práctica a través de ejercicios fonotécnicos mediante el libro de texto y en otros casos, cuadernillos o fichas

Fernández-Rufete Navarro, A (2015): Enseñanza de la ortografía, tratamiento didáctico y consideraciones de los docentes de Educación Primaria de la provincia de Almería, Investigaciones Sobre Lectura, 4, 7-24.
ISL, vol. 4, 2015, págs. 7-24 ISNN: 2340-8685 
refuerzo que promueven la automatización. Según Catalá $(2009$, p. 1), "la enseñanza de la ortografía de forma tradicional no consigue fijar el aprendizaje de los alumnos, (....). Determinadas prácticas, en vez de prevenir los errores ortográficos, contribuyen a fijarlos".

El enfoque socio-constructivista pretenden alejarse de la visión tradicional basando la adquisición de la ortografía en la construcción comunicativa donde los errores se transforman en un elemento para aprender, una enseñanza vinculada a procesos de comprensión y producción textual. Junto a este enfoque, hallamos el comunicativo y funcional donde se proponen situaciones comunicativas para que los alumnos pongan en juego sus conocimientos y, a partir de la revisión holística de sus propios textos, que le servirán como modelo para alcanzar la eficiencia en la comunicación; a través del cual la ortografía recibe un tratamiento más contextualizado dentro de la comprensión y expresión escrita (Barberá, Collado, Morató, Pellicer y Rizo, 2001). Unido a ello, nuevas tendencias nos llevan al enfoque $P N L$ que consiste en "nuevo enfoque de la comunicación y del cambio entre cuyos objetivos está el describir los procesos mentales de forma suficientemente clara como para que puedan ser enseñados" (Gabarró y Puigarnau, 2010, p.29). En el campo de la ortografía, el PNL ha logrado desmenuzar el proceso mental que realizan las personas con buena ortografía y pensando el modo de enseñarlo (Gabarró y Puigarnau, 2010).

A partir de la constatación de que cada día el alumnado lee cada vez menos, existen distintas opiniones de que la lectura es fundamentales para mejorar la ortografía del alumnado. Sánchez (2009, p.16) considera que "la lectura es un óptimo auxiliar de la ortografía porque contribuye a reforzar la imagen léxica que tiene el alumno de las palabras, afianzando el léxico que ya conoce". Hay que inculcarles a nuestros alumnos la necesidad de leer, pues nadie duda de que la lectura sea una gran ayuda para aprender la ortografía de las palabras (García, 2011). En cualquier Plan de Fomento a la lectura podemos ver que su objetivo general es el de utilizar la lectura como medio para aprender vocabulario y ortografía. Martínez de Sousa (2003) apuesta por sacar partido a la lectura para exponer las reglas, subrayar aspectos ortográficos o incluso hacer hincapié en las dificultades.

A pesar de que a las nuevas tecnologías se les atribuye un carácter perjudicial en el ámbito de la ortografía, existen propuestas y estudios que demuestran que una aplicación adecuada de las TIC en el aula puede ser una herramienta efectiva para mejorar la ortografía. Un estudio realizado por la Universidad Autónoma de Barcelona, la Universidad Ramon Llull y el centro CETEI-Fundación Joan XXIII nos muestra evidencias de que estudiantes de secundaria que utilizan contenidos digitales en el aula mejoran un 20\% en las pruebas de ortografía (Marqués, 2011). Por tanto, si se utilizan las nuevas tecnologías de forma adecuada pueden convertirse en nuevos enfoques didácticos que reducen las faltas de ortografía.

ISL, vol. 4, 2015, págs. 7-24 ISNN: 2340-8685
Fernández-Rufete Navarro, A (2015): Enseñanza de la ortografía, tratamiento didáctico y consideraciones de los docentes de Educación Primaria de la provincia de Almería, Investigaciones Sobre Lectura, 4, 7-24. 
Como docentes, debemos evitar hacer un tratamiento de la ortografía basado, exclusivamente, en el aprendizaje de reglas ortográficas; debemos intentar que el alumnado se adueñe de la norma ortográfica y, para ello, es necesario considerar la ortografía como un subproceso en la producción de textos. Es más fácil controlar el número de errores ortográficos que cometen los discentes si se usa más de un método, técnicas e incluso estrategia de aprendizaje (Carratalá, 2002). Por tanto, hemos de optar por diversos métodos o estrategias que consigan darle a la ortografía un tratamiento global.

En lo que respecta a la puesta en práctica de esta enseñanza y aprendizaje de la ortografía, García (2011) y Paredes (1997) plantean la necesidad de trabajarla no solo en el área de Lengua Castellana y Literatura sino en las distintas materias, introducirla en la rutina de aula y de esta manera, los discentes percibirán que cometer faltas de ortografía no solo se ciñe a la área de Lengua adquiriendo la ortografía una perspectiva multidisciplinar.

\subsection{Importancia de la ortografía y su vínculo con la composición escrita}

A lo largo de las distintas etapas, el protagonismo que se le ha ido dando a la ortografía se ha encontrado directamente ligados con la enseñanza; y vinculada al aprendizaje de la lengua escrita. Según Camps et al. (2004), las funciones más importantes de un código gráfico pueden analizarse en dos planos: el plano lingüístico y comunicativo, de un lado; el plano sociológico, de otro. En primer lugar, en el plano lingüístico y comunicativo, el sistema ortográfico asegura la transmisión íntegra y no ambigua de los enunciados aclarando el discurso escrito y, en el plano sociológico, la ortografía constituye un convenio necesario para que todos los miembros de una comunidad lingüística puedan asumir como pertenecientes al grupo. Para Barberá et al. (2001), la ortografía es un elemento unificador, hilo conductor, sintetizador cultural y elemento normalizador.

El aprendizaje de la norma ortográfica comienza cuando el alumno toma contacto con la escritura puesto que constituye un elemento esencial para poder comunicarnos y entendernos, ya que, incluso, un cambio ortográfico puede suponer que la palabra cambie totalmente de significado pudiendo llevar a la incomprensión. Es por ello que numerosos autores defiende la necesidad de aprender ortografía a través de la composición escrita. Gil (2014, p.1) señala que "aprender a escribir correctamente sin faltas de ortografía, es una de las principales prioridades de la enseñanza curricular en la Educación Primaria” y a partir de aquí, nos preguntamos si es necesario dominar las reglas ortográficas antes de aprender a escribir, redactar o expresar ideas. Echauri (2000) percibe que el profesorado está acostumbrado a trabajar la ortografía alejada de aspectos lingüísticos y descontextualizada de la composición escrita, a través de materiales que solo propician el aprendizaje memorístico de reglas. Según Mesanza (2003, p. 222), "la ortografía definida por la RAE como la parte de la gramática que

Fernández-Rufete Navarro, A (2015): Enseñanza de la ortografía, tratamiento didáctico y consideraciones de los docentes de Educación Primaria de la provincia de Almería, Investigaciones Sobre Lectura, 4, 7-24.
ISL, vol. 4, 2015, págs. 7-24 ISNN: 2340-8685 
enseña a escribir correctamente por el acertado empleo de las letras y de los signos auxiliares de la ortografía, se valora como un aspectos más de lo escrito". Por tanto, las actividades y recursos empleados para el tratamiento de la ortografía deben basarse en el discurso escrito a través de la creación y revisión de textos (Galera y Camps, 2002 citado en Mesanza, 2003).

Vincular la enseñanza de ortografía a la composición de texto permitiría trabajarla de manera contextualizada y por ello, "el problema de la enseñanza de la ortografía no puede separarse del problema de la enseñanza de la escritura" (Echauri, 2000, p.1). Según Navarre (2010 citado en Gil, 2014, p.1) "a escribir se aprende escribiendo y leyendo". Esta perspectiva de enseñanza apuesta por la composición escrita como medio por el que aprender las reglas ortografía y gramaticales. Junto a ello, es necesario incluir la corrección ortográfica durante el proceso de escritura donde se trabajaría la autocorrección y la revisión. (Cassany, 1999 citado en Echauri, 2000). En la actualidad, hay experiencias didácticas en las que se manejan recursos para componer textos, como son la creación de cuentos ortográficos, cartas o mensajes electrónicos. Siguiendo estas propuestas, "la ortografía por tanto, en los procesos de lectura y escritura ocupa en estos un sitio privilegiado" (Abello-Cruz, 2010, p.54).

En definitiva, la gran relevancia que presenta la ortografía para Mesanza (1991) reside en la estrecha relación entre la capacidad ortográfica con otras facetas lingüísticas como pueden ser la lectura, composición escrita, lingüística, pronunciación, gramática, el significado de los vocablos, entre otras; de ahí que sea necesario trabajarla como un aspecto no aislado en la formación lingüística de los discentes.

\subsection{Marco o conexión curricular}

En este marco curricular se vincula la actual Ley Orgánica 2/2006, de 3 de mayo, de Educación, en su artículo 6.2, donde se fijan los aspectos básicos del currículo que constituyen las enseñanzas mínimas y a su vez, el Decreto $n^{\circ}$ 230/2007 de 31 de julio, por el que se establece la ordenación y las enseñanzas correspondientes a la Educación Primaria en Andalucía se regula la enseñanza del Área de Lengua Castellana y Literatura, las cuales muestran una serie de evidencias sobre el correcto conocimiento ortográfico como medio para desarrollar la competencia comunicativa y social de los niños que reflejan estas leyes educativa.

El Real Decreto 1513/2006, de 7 de diciembre, por el que se establecen las enseñanzas mínimas de la Educación primaria, en asignatura de Lengua Castellana y Literatura se pretende "consolidar en esta etapa el dominio de las técnicas gráficas, la relación sonido-grafía, las normas ortográficas convencionales”. (MEC, 2006, p. 43083) En el ámbito curricular, la ortografía se halla dentro del área de conocimiento de "Lengua castellana y literatura" haciendo mención a la ortografía en los siguientes objetivos de la etapa de Educación Primaria: "Comprender y expresarse oralmente y por

ISL, vol. 4, 2015, págs. 7-24 ISNN: 2340-8685
Fernández-Rufete Navarro, A (2015): Enseñanza de la ortografía, tratamiento didáctico y consideraciones de los docentes de Educación Primaria de la provincia de Almería, Investigaciones Sobre Lectura, 4, 7-24. 
escrito de forma adecuada en los diferentes contextos de la actividad social y cultura" y "Hacer uso de los conocimientos sobre la lengua y las normas de uso lingüístico para escribir y hablar de forma adecuada, coherente y correcta, y para comprender textos orales y escritos" (MEC, 2006, p. 43084). Por último, en los contenidos del área, tenemos que tener en cuenta el conocimiento y el uso reflexivo del código lingüístico oral y escrito- en los niveles de oración, de palabra y de texto y es en el bloque del área, donde se han de consolidar el dominio de las técnicas gráficas, la relación sonidografía, las normas ortográficas convencionales y la disposición del texto en la página, teniendo en cuenta que la incorporación de las tecnologías de la información y la comunicación.

En el Decreto $n^{\circ} 230 / 2007$ de 31 de julio, la ortografía aparece en el núcleo temático “¿Qué y cómo escribir?” se proponen sugerencias sobre líneas metodológicas y utilización de recursos, en concreto: "El proceso escritor debe iniciarse con la redacción de mensajes sencillos con una intención clara y funcional. Más tarde se abordará la composición de mensajes más complejos con un conocimiento básico de los elementos que participan en la composición" donde el alumnado adquirirá en esta etapa un nivel de expresión escrita "con corrección ortográfica y gramatical" (BOJA, 2007, p.18). Por último, en la Ley Orgánica 2/2006, de 3 de mayo de Educación, en el artículo 19.2. Principios pedagógicos destaca la necesidad de realizar un tratamiento interdisciplinar de elementos propios del lenguaje como es la ortografía.

\subsection{Objetivos de la investigación}

Este estudio tiene como objetivo indagar y disponer de información sobre la enseñanza de la ortografía que lleva a cabo el profesorado de Educación Primaria en el área de Lengua y Literatura en lo que respecta a planteamientos didácticos; técnicas; enfoques; prácticas metodológicas; tipo de evaluación y recursos para su enseñanza, con la finalidad de valorar la situación actual y promover nuevos cambios y propuestas.

\subsubsection{Objetivo general}

- Conocer cómo se lleva a cabo la enseñanza aprendizaje de la ortografía a través de la información aportada por los docentes que importan el Área de Lengua y Literatura en Educación Primaria.

\subsubsection{Objetivos específicos}

- Analizar los planteamientos didácticos utilizados para trabajar la ortografía en el aula.

- Conocer que metodología emplea el profesorado para trabajar la ortografía en el aula. 
- Obtener una visión de la problemática de la enseñanza de la ortografía desde la perspectiva práctica de los maestros.

- Conocer cómo los docentes trabajan la corrección de errores ortográficos.

- Evaluar el grado de satisfacción de los docentes en la enseñanza de la ortografía y recabar sus aportaciones.

- Conocer la postura del profesorado ante la influencia de las TIC en el alumnado y su utilización como recurso para la enseñanza de la ortografía.

\section{Método}

\subsection{Enfoque o perspectiva de investigación cuantitativa: La investigación descriptiva}

Este estudio se inscribe dentro del paradigma de investigación de ámbito cuantitativo y la modalidad de investigación es no experimental. Este enfoque de investigación:

Utiliza la recolección y el análisis de datos para contestar preguntas de investigación y probar hipótesis establecidas previamente, y confía en la medición numérica, el conteo y frecuentemente en el uso de la estadística para establecer con exactitud patrones de comportamiento en una población (Hernández, Fernández y Baptista, 2003, p.5).

Se trata de una investigación no experimental descriptiva, la cual nos permite estudiar el problema educativo y lograr los objetivos de la investigación. Este estudio centra su atención en determinar el "qué es" de un fenómeno educativo, en este caso, la situación de la importancia concedida a la ortografía y su tratamiento en las aulas de Primaria en Almería y provincia desde la actividad de los docentes, lo que supone una descripción pormenorizada del estado actual de esta situación educativa. En definitiva, se centra en medir, recolectar o evaluar datos referidos a distintos aspectos, dimensiones o componentes del fenómeno a investigar (Hernández et al., 2003). Se recoge y analiza información con fines exploratorios para llegar a contrastar las hipótesis planteadas (Arnal, Latorre y Del Rincón, 1994), donde utilizaremos un cuestionario como instrumento de recogida de datos para la medición objetiva de este fenómeno social. La meta es proporcionar descripciones estadísticas, relaciones y explicaciones (McMillan y Schumacher, 2005).

En una investigación descriptiva, McMillan y Schumacher (2005, p.42) consideran que "el propósito se limita a caracterizar algo como es". Con esta investigación, se van a describir las características de la enseñanza de la ortografía, en lo que respecta a planteamientos didácticos y otras consideraciones, a través de la información recogida de los docentes encuestados. La estrategia de investigación empleada es la encuesta que esta "orientada a la descripción de una situación dada" (Arnal et al., 1994, p.175), donde conseguiremos información de una parte

ISL, vol. 4, 2015, págs. 7-24 ISNN: $2340-8685$
Fernández-Rufete Navarro, A (2015): Enseñanza de la ortografía, tratamiento didáctico y consideraciones de los docentes de Educación Primaria de la provincia de Almería, Investigaciones Sobre Lectura, 4, 7-24. 
representativa de la población objeto y con esa muestra extraer conclusiones representativas (Bell, 2001).

\subsection{Contexto y participantes}

En esta investigación, la población objeto se localizan en la provincia de Almería donde se necesita recoger el mayor número de información de los docentes que imparten el área de Lengua y Literatura Castellana con el objetivo de poder generalizar y estudiar esta problemática. El contexto lo conforman los colegios de Educación Primaria de Almería y provincia, tanto públicos como privados y concertados, donde los participantes serán los profesores que imparten el área de Lengua Castellana y Literatura. El tipo de muestreo utilizado es el muestreo aleatorio simple donde "los sujetos son seleccionados a partir de la población, de tal manera que todos los miembros de la población tienen la misma probabilidad de resultar escogidos" (McMillan y Schumacher, 2005, p.136) que aporta validez externa a la investigación.

Según los propósitos del estudio, se consideró relevante tomar en cuenta al mayor número posible de profesores pertenecientes al área de Lengua y Literatura de Educación Primaria de los centros educativos de la Almería y provincia para obtener una muestra representativa, de modo que la muestra está constituida por un total de 140 profesores pertenecientes a 25 centros educativos de distintas localidades de la Almería y provincia recogidos en la siguiente tabla.

\begin{tabular}{|c|c|}
\hline \multicolumn{2}{|c|}{ CENTROS EDUCATIVOS COLABORADORES } \\
\hline CENTRO EDUCATIVO & LOCALIDAD \\
\hline CEIP “Álvarez Sotomayor” & Cuevas de Almanzora (Almería) \\
\hline CEIP "Ángel del Haro" & Vera (Almería) \\
\hline CEIP "Antonia Artigas" & Gérgal (Almería) \\
\hline CDPC “Arcangel” & Almería (Almería) \\
\hline CDPC. "Divina Infantita" & Almería (Almería) \\
\hline CEIP. "Emilio Zurano Muñoz" & Pulpí (Almería) \\
\hline CEIP. "Freinet" & Almería (Almería) \\
\hline CEIP. "FuenteSantilla" & Puente del Río (Adra) \\
\hline CEIP. “Joaquín Tena Sicilia” & Abla (Almería) \\
\hline CEIP. "Josefina Baro Soler" & El Puche, Almería (Almería) \\
\hline CEIP. "La Atalaya" & Níjar (Níjar) \\
\hline CDPC. "La Milagrosa" & Almería (Almería) \\
\hline CEIP. "Lope de Vega" & Almería (Almería) \\
\hline CDPC. "Mader Asunta" & Almería (Almería) \\
\hline CEIP. "Madre de la Luz" & Almería (Almería) \\
\hline CEIP. "Padre Méndez" & Almería (Almería) \\
\hline CEIP. "Príncipe Felipe" & Huercal-overa (Almería) \\
\hline CEIP. "San Agustín" & San Agustín (El Ejido) \\
\hline CC. "San Francisco" & Almería (Almería) \\
\hline
\end{tabular}

Fernández-Rufete Navarro, A (2015): Enseñanza de la ortografía, tratamiento didáctico y consideraciones de los docentes de Educación Primaria de la provincia de Almería, Investigaciones 


\begin{tabular}{|l|l|}
\hline CEIP. “San Nicolás" & Adra (Almería) \\
\hline CEIP. “Simón Fuentes" & Carboneras (Almería) \\
\hline CDPC. "Stella Maris" & Almería (Almería) \\
\hline CEIP. "Tres Villas-Nacimiento" & Nacimiento (Almería) \\
\hline CEIP. "Castillo de los Vélez" & Vélez-blanco (Almería) \\
\hline CEIP. "Velázquez" & Albox (Almería) \\
\hline
\end{tabular}

Tabla 1. Centros educativos de Almería y municipios participantes en la investigación.

\subsection{Recogida de información: instrumentos y procedimientos}

En esta investigación descriptiva, el cuestionario es el instrumento utilizado para recoger los datos; es decir, el listado de preguntas a las que debe responder la muestra previamente seleccionada y además, especifica el modo de respuesta que ofrecerán (Cea, 2001, citado en Quintanal y García, 2012); para obtener información de primera mano y, por tanto, la recolección sistemática de datos para establecer conclusiones.

Este cuestionario consta de 20 preguntas donde figuran aspectos relacionados con la consideración de la ortografía, su tratamiento en el aula, enfoques, las nuevas estrategias, la corrección de la misma, la inclusión de las tecnologías de la información y comunicación entre otros, es decir, distintos contenidos pedagógicos del área de lengua relacionados con la ortografía. En él, se incluyen preguntas abiertas y cerradas cuyas respuestas están acotadas en la encuesta pero con varias opciones de respuesta. Para cerciorarme de la validez de este instrumento y como medio de validación del mismo, llevé a cabo una prueba piloto con 10 docentes de la muestra y expertos en la temática lo revisaron y analizaron con el fin de validarlo (Casas et al., 2006) y cercionarnos de que se recoge información válida y fiable sobre aquello que se plantea en la investigación (Hernández et al., 2003). Vinculado a la difusión del instrumento, los cuestionarios fueron enviados por correo electrónico y entregados de manera personal en algunos de los centros, junto al cuestionario se incluía una carta de presentación y unas instrucciones sencillas a tener en cuenta para su cumplimentación y devolución.

El proceso de recogida de datos tuvo lugar entre marzo y mayo donde se obtuvieron un total de 140 cuestionarios de la muestra. Una vez recopilados los datos, se realizó un tratamiento de la información obtenida sometiendo a análisis los datos donde se revisaron, recopilaron y categorizaron los datos clasificándolos según respuestas dadas a los distintos ítems de las preguntas que se contabilizaron en tablas de frecuencia, para su posterior análisis estadístico y obtención de representaciones gráficas en forma de diagramas de barras y gráficos de sectores para la interpretación de los resultados. A su vez, para expresar en porcentaje los datos cuantitativos se definieron unas unidades de codificación determinando categorías, es decir, se crearon patrones generales de respuesta y la asignación de un valor numérico a cada patrón para

ISL, vol. 4, 2015, págs. 7-24 ISNN: 2340-8685
Fernández-Rufete Navarro, A (2015): Enseñanza de la ortografía, tratamiento didáctico y consideraciones de los docentes de Educación Primaria de la provincia de Almería, Investigaciones Sobre Lectura, 4, 7-24. 
medir la frecuencia de aparición. Finalmente, al disponer categorizados todos los datos, obtenemos unos datos que se exponen a continuación.

\subsection{Datos y resultados}

Este apartado tiene la finalidad de describir y analizar los resultados obtenidos para poder sacar conclusiones y realizar una valoración de la enseñanza de la ortografía en todos los aspectos propuestos. A continuación, se analizaran los resultados más significativos tomando como referente los resultados de la encuesta realizada al profesorado e interpretando los gráficos realizados, seleccionando los siguientes:

1. Consideración de la ortografía (figura 1). El profesorado, en un $90 \%$, manifiesta que la ortografía es un elemento clave en la enseñanza de la Lengua por encima de otros aspectos como la gramática, un $4 \%$ la considera menos importante que la gramática, solo un $2 \%$ no lo considera clave en la enseñanza de la Lengua, y finamente, otras consideraciones aportadas por un $4 \%$ de los docentes. De entre estas últimas destacar: la lectura; el vocabulario y gramática como elementos claves de la enseñanza de la lengua.

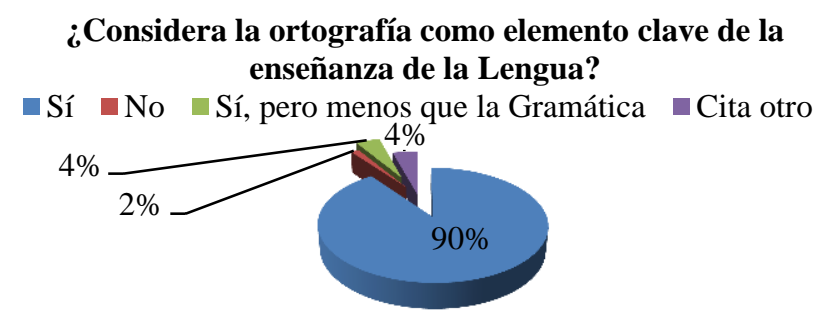

Figura 1. Consideración de la ortografía.

2. Satisfacción con los niveles ortográficos obtenidos por el alumnado (figura 2). En general, el $66 \%$ del profesorado se muestra insatisfecho con los niveles ortográficos obtenidos por el alumnado, en contraposición con un $31 \%$ que afirma que sí se encuentran satisfechos con estos niveles y un $3 \%$ que NS/NC.

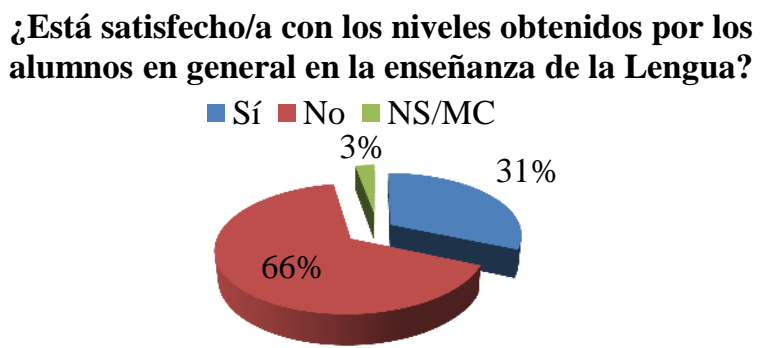

Figura 2. Satisfacción con los niveles ortográficos obtenidos por el alumnado.

3. Consideración del fracaso ortográfico generalizado en diversos niveles educativos (figura 3). El $76 \%$ los encuestados reconocen que existe este fracaso generalizado que afecta a un elevadísimo número de escolares de los distintos niveles educativos, solo un $13 \%$ considera que no lo hay, un $7 \%$ que cree que el fracaso es circunstancial y, solamente, $4 \%$ de los docentes NS/NC.

Fernández-Rufete Navarro, A (2015): Enseñanza de la ortografía, tratamiento didáctico y consideraciones de los docentes de Educación Primaria de la provincia de Almería, Investigaciones Sobre Lectura, 4, 7-24.
ISL, vol. 4, 2015, págs. 7-24 ISNN: 2340-8685 
¿Considera que existe un fracaso ortográfico generalizado que afecta a un elevadísimo número de escolares de los distintos niveles educativos?

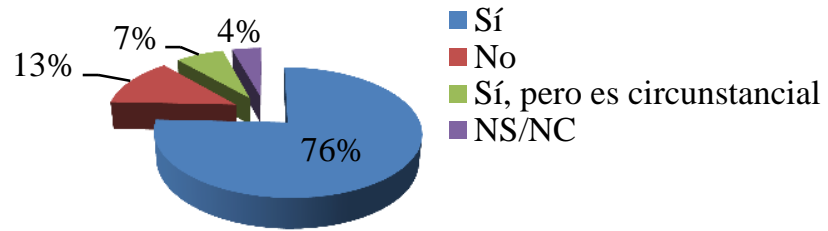

Figura 3. Consideración del fracaso ortográfico generalizado en diversos niveles educativos.

4. Enfoques metodológicos en la enseñanza de la ortografía (figura 4). En lo que concierne al tipo de enfoque metodológico empleado por los docentes en el área de Lengua, encontramos ciertas discrepancias: la mezcla de enfoques predominan con un $75 \%$, a los que siguen el constructivista o comunicativo, con un $12 \%$; el enfoque tradicional o academicista utilizado por un $9 \%$, el $1 \%$ NS/NC y, por último, otros métodos, con un 3\% entre los que destacar: trabajar con vocabulario y hacer uso de juegos con el lenguaje.

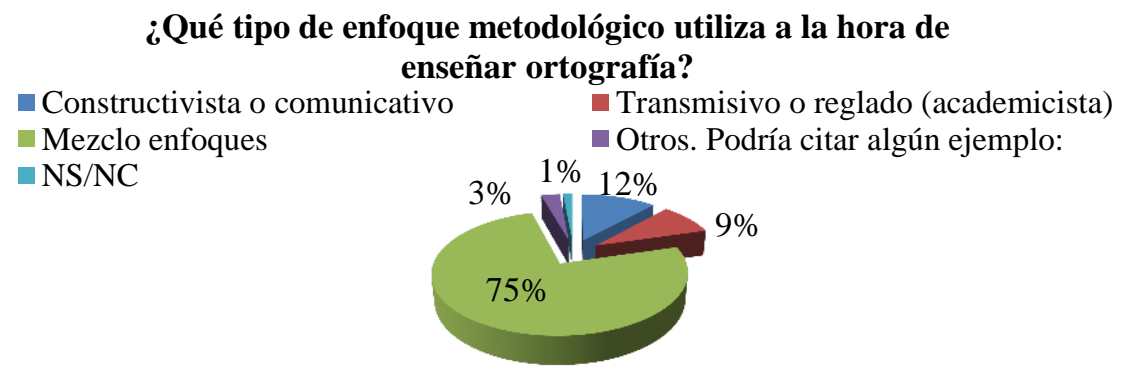

Figura 4. Enfoques metodológicos en la enseñanza de la ortografía

5. Enseñanza de la ortografía bajo propuestas tradicionales (figura 5). Aunque la mayoría de los encuestados emplean para trabajar con la ortografía propuestas tradicionales como los dictados y la corrección de los mismos, también, encontramos: un 64\% opina que estas propuestas tradicionales pueden servir de base, pero se deben promover alternativas, un $18 \%$ que considera que estas propuestas deben eliminarse y plantear nuevas a través de actividades de revisiones textuales, autocorrección, juegos de lenguaje, etc. y de otro, que un $16 \%$ cree que es necesario revisarse y consensuarse nuevos métodos y solo un $2 \%$ aporta otras alternativas, entre ellas: el dictado como estrategia que debe complementarse con otros métodos; juegos con el lenguaje; y la lectura.

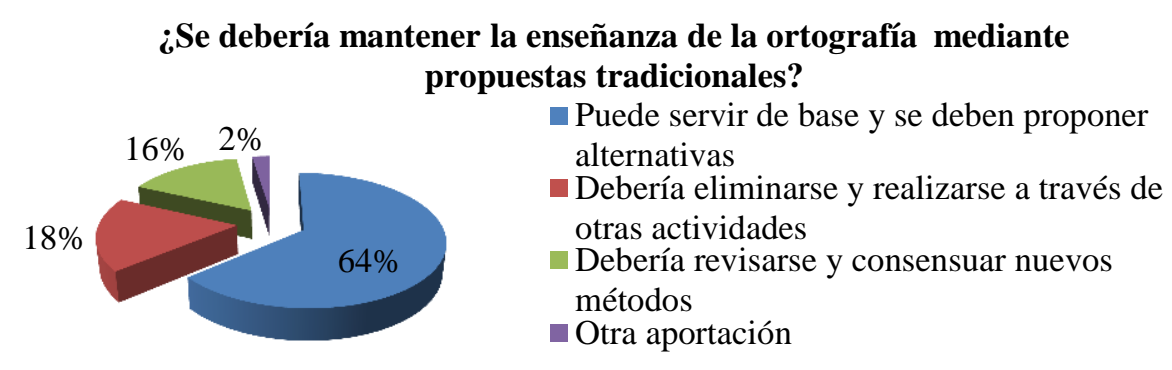

Figura 5. Enseñanza de la ortografía bajo propuestas tradicionales.

ISL, vol. 4, 2015, págs. 7-24 ISNN: $2340-8685$
Fernández-Rufete Navarro, A (2015): Enseñanza de la ortografía, tratamiento didáctico y consideraciones de los docentes de Educación Primaria de la provincia de Almería, Investigaciones Sobre Lectura, 4, 7-24. 
6. Importancia de la ortografía en todas las áreas de conocimiento, no solo la de Lengua (figura 6). En cuanto, a la consideración de la ortografía como un aspecto que debería tener igual importancia en todas las áreas de conocimiento y no solamente en el área de Lengua, el 99\% del profesorado considera que se debe dar la misma importancia a la ortografía en todas las áreas y un 1\%, que no en todas las áreas.

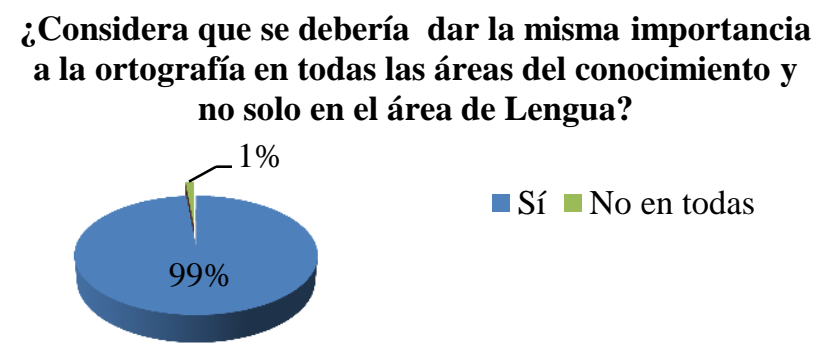

Figura 6. Importancia de la ortografía en todas las áreas de conocimiento.

7. Nuevas estrategias para la enseñanza de la ortografía (Figura 7). Vinculado a las nuevas estrategias para la enseñanza de la ortografía, el 31\% del profesorado considera que las nuevas estrategias deben basarse en lecturas de textos seleccionados, motivadores, que conecten con su entorno, sus interés, su imaginación, sus experiencias, su nivel de maduración personal..., un $29 \%$ en la autocorrección y juegos con el lenguaje; el 25\% cree que partir de la producción de textos propios constituiría una nueva estrategia y, finalmente, solo un $14 \%$ de los docentes encuestados defienden la deducción de normas y búsqueda de irregularidades ortográficas en sus producciones; y por último, un 1\% otras: uso del diccionario y propuestas TIC.

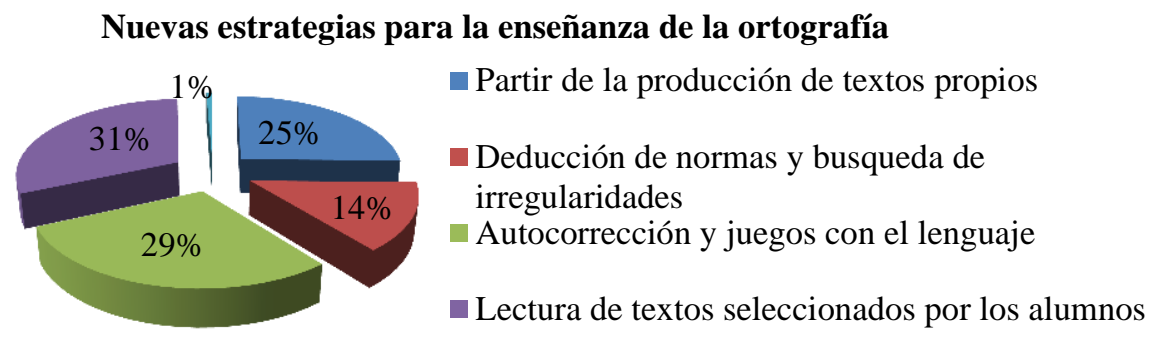

Figura 7. Nuevas estrategias para la enseñanza de la ortografía.

8. Trabajar la ortografía a través de textos propios en clase (figura 8). Aunque, podemos percibir cómo el profesorado apuesta por propuestas más tradicionales como el dictado, si bien existe la posibilidad de vincular la ortografía a la producción escrita, el 59\% trabaja, a menudo, con la ortografía a través de la producción de textos propios, repasando borradores y haciendo revisiones para obtener la producción final. Por el contrario, el 31\% lo realiza ocasionalmente y, de manera trimestral, un $10 \%$. 


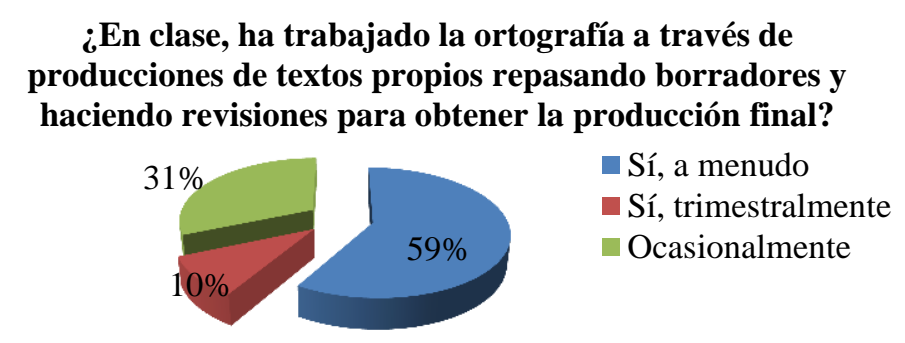

Figura 8. Trabajar la ortografía a través de producción de textos

\section{Conclusiones, consecuencias e implicaciones.}

A la vista de los resultados obtenidos a través del cuestionario, es posible establecer ciertas conclusiones. En cuanto a los propósitos de esta investigación, la mayoría de los objetivos planteados se han verificado y, además, se ha conseguido conocer cuál es la visión general de la situación de la enseñanza aprendizaje de la ortografía desde el punto de vista de los docentes que imparten el Área de Lengua y Literatura en Educación Primaria en Almería y provincia. A continuación, destaco brevemente las conclusiones, consecuencias e implicaciones obtenidas:

En primer lugar, queda reflejada la importancia de la ortografía para el profesorado y la consideración de elemento clave en la enseñanza de la Lengua, a lo que se añade la constatación de la insatisfacción y preocupación por los niveles ortográficos obtenidos por el alumnado y el reconocimiento de un fracaso ortográfico que afecta a un elevado número de escolares. Aún así, esta insatisfacción manifestada no se ve reflejada en un cambio metodológico e instrumental patente, pero sí se aprecia una tendencia y predisposición general del profesorado hacia la adopción de nuevas técnicas y herramientas que, en su opinión, deberían ser incluidas en las programaciones y libros de texto. Los docentes siguen recurriendo al libro de texto para trabajar la ortografía aunque saben que las actividades que plantea son insuficientes para trabajarla viendo la necesidad de promover alternativas. A pesar de estar predispuestos a recurrir a nuevas propuesta, se mantiene como técnicas e instrumentos más empleados para los dictados, los libros de texto y copiados.

En segundo lugar, existe una intención de promover cambios en la enseñanza, pero las programaciones de aula son las que parecen limitar estos cambios, situación que puede revertir el propio profesorado realizando nuevas programaciones $\mathrm{y}$ promoviendo los cambios en los libros de texto. Sin duda, las limitaciones en el horario y el número de alumnos por clase son también destacados en las observaciones del profesorado como limitantes a la hora de iniciar nuevas técnicas o métodos de enseñanza de la ortografía.

En tercer lugar, tras observar los resultados de la investigación y recogiendo las observaciones del profesorado, se considera que es fundamental enseñar ortografía a través de actividades que impliquen composición escrita, fundamentalmente, la

ISL, vol. 4, 2015, págs. 7-24 ISNN: 2340-8685
Fernández-Rufete Navarro, A (2015): Enseñanza de la ortografía, tratamiento didáctico y consideraciones de los docentes de Educación Primaria de la provincia de Almería, Investigaciones Sobre Lectura, 4, 7-24. 
producción de textos propios por parte del alumnado. Se puede considerar imprescindible que la enseñanza de la ortografía esté ligada a la comunicación oral y escrita, lo que llevaría a la reflexión sobre si el problema de la enseñanza de la ortografía puede considerarse un problema solo de la enseñanza de la escritura o si, por el contrario, se ha de plantear desde una perspectiva global y hacerse necesario desarrollar un cambio profundo en la manera de abordar su enseñanza en las aulas.

Este estudio revela que el papel del profesorado es clave en la enseñanza de la ortografía junto a la responsabilidad de crear situaciones que favorezcan los aprendizajes de los discentes. Evidentemente, existe una problemática y el profesorado, para poder reducir estas dificultades ortográficas y acatar el problema, necesita buscar nuevos métodos, asumir las causas y las dificultades proponiendo nuevas estrategias que se adapten a la realidad y a las necesidades del alumnado; actualmente el tratamiento que proporciona el profesorado del área de Lengua Castellana y Literatura en general nos lleva a pensar en una actividad descontextualizada que guarda poco relación con la actividad de composición escrita y que se encuentra limitada por las programaciones del aula. Existe, pues, una carencia de planteamientos comunicativos lo suficientemente motivadores para el alumnado y se llevan a cabo pocas propuestas alternativas de carácter didáctico donde se incluyan producción de textos significativos por parte del alumnado, "juegos con palabras" o modelos visuales que propicien la escritura correcta. Según Solé (1994), es necesario plantear pequeños cambios en nuestra práctica docente e intentar que la enseñanza de la Lengua se lleve a cabo mediante un enfoque mucho más comunicativo $\mathrm{y}$ funcional. Las propuestas comunicativas enfatizan el impulso de las cuatro habilidades básicas: hablar, escuchar, leer y escribir (Cassany, Luna y Sanz, 1993 citado en Solé, 1994).

Por otra parte, convendría responsabilizar al profesorado de todas las áreas, no solo del área de Lengua Castellana y Literatura, de la concesión de su valor y de su contemplación, de corregirla y evaluarla. Para que la ortografía deje de ser una preocupación, es necesario que la responsabilidad recaiga sobre todos los actores, incluido el profesorado, por lo que ha de ser incluida en las programaciones de las asignaturas durante el todo el periodo escolar. Para Mesanza (1991) y García (2011) la ortografía es algo que compete a todo el profesorado, no solo a los especialistas del área de Lengua. El profesorado reconoce que la ortografía afecta no solamente en el área de Lengua Castellana y Literatura, sino en Educación Primaria, ya que del aprender a escribir correctamente dependerá, en gran parte, el éxito de su formación posterior. La competencia ortográfica solo se puede mejorar a través de propuestas innovadoras que se gesten por el profesorado con el objetivo de mejorarla. Por ello, existe la necesidad de que los profesores que, actualmente, están en los centros unifiquen criterios y consensuen programaciones donde se vaya produciendo cambios sustanciales y duraderos de los enfoques y metodologías a aplicar en la enseñanza de la ortografía. 


\section{Bibliografía}

Abello-Cruz, A.M. (2010). Características y alcance de los cuadernos de actividades de Ortografía. Varona Revista Científico-Metodológica, 50, 54-59. Recuperado el 20 de Marzo, $2014 \quad$ desde http://revistas.mes.edu.cu/greenstone/collect/repo/import/repo/20110707/086419 6X50054.pdf.

Arnal, J., Del Rincón, D. y Latorre, A. (1994). Investigación educativa. Fundamentos y metodología. Barcelona: Labor.

Barberá, V., Collado, J.C, Morató, J., Pellicer, C. y Rizo, M. (2001). Didáctica de la ortografía. Estrategias para su aplicación práctica. Madrid: Ceac.

Bell, J. (2002). Cómo hacer tu primer trabajo de investigación: guía para investigadores en educación y ciencias sociales. Barcelona: Gedisa.

Belocón, O. y Dotti, E. (2007). La ortografía: ¿problemática o problematizadora? Revista Quehacer educativo, 75-81. Recuperado el 23 de Marzo, 2014 de http://www.quehacereducativo.edu.uy/docs/81bd8097_86-014.pdf.

Bustos, M. (1995). Breve ortografía escolar. Barcelona: Octaedro.

Casas, J., García, J. y González, F. (2006, Abril 24). Guía técnica para la construcción de cuestionarios. Odiseo: Revista electrónica de pedagogía, 6(3). Recuperado el 10 Mayo, 2014 de http://www.odiseo.com.mx/2006/01/casas_garcia_gonzalezguia.htm.

Camps, A.; Millán, M.; Montserrat, B. y Cabré, P. (2004). La enseñanza de la ortografía ( $3^{\mathrm{a} e d}$.). Barcelona: Graó.

Catalá, B. (2009). "La ortografía, un problema tradicional". Recuperado el 10 Marzo, 2014 de www.instituto127.com.ar/Alumnos/.../lenguaedi2ortografia_catala.doc.

Cea, M. A. (2001). Metodología cuantitativa. Estrategias y técnicas de investigación social. Madrid: Síntesis sociología.

Díaz, M. R. (2008). Preocupaciones docentes y enfoque didáctico de la enseñanza de la ortografía. Revista docencia e investigación, 8, 18. Recuperado el 30 Marzo, 2014

de http://www.uclm.es/varios/revistas/docenciaeinvestigacion/pdf/numero8/rosario diaz_perea.doc.

Echauri, J. M. (2000). ¿Reformar la ortografía o reformar la enseñanza de la ortografía? Cuadernos de Cervantes, 6 (30), 22-27. Recuperado el 11 de Marzo, 2014 de http://www.cuadernoscervantes.com/art_30_ortografia.html.

ISL, vol. 4, 2015, págs. 7-24 ISNN: $2340-8685$
Fernández-Rufete Navarro, A (2015): Enseñanza de la ortografía, tratamiento didáctico y consideraciones de los docentes de Educación Primaria de la provincia de Almería, Investigaciones Sobre Lectura, 4, 7-24. 
Enseñanza de la ortografía, tratamiento didáctico y consideraciones de los docentes... 23

España. Ley Orgánica de Educación del 2/2006 de 3 de mayo. Boletín Oficial del Estado, 4 de mayo de 2006, núm. 106, p. 17168.

España. Real Decreto-ley 230/2007, de 10 de agosto, por el que se establece la ordenación y las enseñanzas correspondientes a la educación primaria en Andalucía. Boletín Oficial del Estado, 30 de agosto de 2007, núm. 171, pp. 1518.

España. Real Decreto-ley 1513/2006, de 7 de diciembre, por el que se establecen las enseñanzas mínimas de la Educación primaria. Boletín Oficial del Estado, 8 de diciembre de 2006, núm. 29, pp. 43083-43084.

Gabarró, D. y Puigarnau, C. (2010). Buena Ortografía sin esfuerzo con PNL. Propuesta metodológica para docentes. Barcelona: Boira.

García, C. (2011). Escribir correcto: la importancia de la ortografía. Revista Extremeña sobre Formación y Educación. (2), 1. Recuperado el 2 de abril, 2014 de http://revista.academiamaestre.es/2011/01/escribir-correcto-la-importancia-dela-ortografia/.

García, L. (2001). La enseñanza - aprendizaje de la ortografía en Cuba: una historia por hacer. Revista Quaderns Digitals, 55. Recuperado el 15 de Abril, 2014 de http://www.quadernsdigitals.net/index.php?accionMenu=hemeroteca.VisualizaA rticuloIU.visualiza\&articulo $\mathrm{id}=107988$.

Gil, I. (2014). El método equivocado para enseñar gramática (y el más utilizado). El Confidencial. Recuperado el 12 de Marzo, 2014 de http://www.elconfidencial.com/alma-corazon-vida/2014-02-27/el-metodoequivocado-para-ensenar-gramatica-y-el-mas-utilizado 94325/.

Gómez, L. (2007). Ortografía escolar. (2a ed.). Madrid: Ediciones SM.

Hernández, R., Fernández, C. y Baptista, P. (2003). Metodología de la investigación. ( $3^{\mathrm{a}} \mathrm{ed}$.). México: McGraw-Hill.

Marquès, P. (2011). Una correcta aplicación de las TIC puede mejorar los resultados académicos. Revista de divulgación científica. Recuperado 9 de Marzo, 2013 dehttp://www.uab.es/servlet/Satellite?cid=1096481466568\&pagename=UABDi vulga/Page/TemplatePageDetallArticleInvestigar\&param1=1318574563769

Martínez, J.A. (2004). Escribir sin faltas: Manual básico de ortografía. Asturias: Nobel.

Martínez de Sousa, J. (2003). Algunos enfoques en la enseñanza de la ortografía. Recuperado el 14 de Marzo, 2014 de http://martinezdesousa.net/.

McMillan, H. y Schumacher, S. (2005). Investigación educativa. Madrid: Pearson.

Fernández-Rufete Navarro, A (2015): Enseñanza de la ortografía, tratamiento didáctico y consideraciones de los docentes de Educación Primaria de la provincia de Almería, Investigaciones Sobre Lectura, 4, 7-24.
ISL, vol. 4, 2015, págs. 7-24 ISNN: 2340-8685 
Mesanza, J. (1991) Didáctica actualizada de la Ortografía. Madrid: Santillana.

Paredes, F. (1997). La ortografía: una visión multidisciplinar. Recuperado el 1 de Abril, 2014 http://cvc.cervantes.es/ensenanza/biblioteca_ele/asele/pdf/08/08_0607.pdf.

Palacios, J. (2010). Ortografía. Manual práctico para escribir mejor. Adaptado de la nueva gramática española. Madrid: RC Libros.

Real Academia Española. (2001). Ortografía. En Diccionario de la lengua española (22. ${ }^{\mathrm{a}}$ ed.). Recuperado de http://lema.rae.es/drae/?val=ortografia

Real Academia Española, (2010). Ortografia básica de la lengua española. Recuperado de http://www.rae.es/obras-academicas/ortografia/ortografia-2010

Salgado, H. (1997). Aprendizaje ortográfico en la didáctica de la escritura. Buenos Aires: Aique.

Sánchez, D. (2009, Junio 16): Una aproximación a la didáctica de la ortografías en las clases de ELE. Revista de didáctica ELE, 9, 1885-2211. Recuperado el 3 de Abril, 2014 de http://marcoele.com/descargas/9/sanchez ortografia.pdf.

Solé, I. (1994). Aprender a usar la Lengua: Implicaciones para la enseñanza. Aula de innovación educativa, 26, p. 5-10.

ISL, vol. 4, 2015, págs. 7-24 ISNN: $2340-8685$
Fernández-Rufete Navarro, A (2015): Enseñanza de la ortografía, tratamiento didáctico y consideraciones de los docentes de Educación Primaria de la provincia de Almería, Investigaciones Sobre Lectura, 4, 7-24. 